\title{
Gold CoAst Is Not OnLy All That GlitTERS UNDERSTANDING VISITOR AND RESIDENT PERCEPTIONS OF THE GOLD COAST
}

\begin{abstract}
Utilising the case study of the Gold Coast Australia, this paper aims to discuss city identity and the role of branding in the formation of the city image and explore whether residents and tourists perceive identity of a city differently. The paper views place identity from the perspective of modern practices of place marketing and branding rather than experiential self-identity. City identity forms the context from which planning policies, plans and decisions are made, making it a significant area of theory in the planning discipline. However, if perception of this identity by outsiders is inaccurate attracting investment and residents will be challenging. The inherent multifaceted nature of city or place identity further emphasises the need for those planning for the multiplicity of communities, suburbs, cities, regions and states to understand the context of those who live within such places.
\end{abstract}

KEYWORDS: Gold Coast, city identity, city image, visitor and resident perceptions

\section{Introduction}

The Gold Coast, located in the South East corner of Queensland in Australia, is a major domestic and international tourist destination with 57 kilometres of coastline. The city attracts more than 9 million tourists annually (Gold Coast Tourism, 2010) and has a resident population of approximately 515,000 people (Australian Bureau of Statistics, 2012). The Gold Coast has a somewhat malleable urban identity that has been molded and changed progressively throughout the city's short history. It is one of those peculiar places that represents different things to different people. The city has been variously described as 'a sunny place for shady people' (Jones, 1986, p.1), 'the most heterogeneous region in Australia' (McRobbie 1991, p.vi), a city experiencing 'adolescence' (Burton, 2009, p.1) and a resort centre that is currently evolving into a city (Edwards et al., 2007). Such representations are likely to be experienced in varying degrees by tourists and residents within the city. As Griffin (1998, p.286) notes of the Gold Coast, there is a 'profusion of competing discourses, constructions, values, perceptions and interests when it comes to planning, defining, imagining (or Imagineering) the city's future urban forms and identities'. He (1998, p.286) further identifies the crux of the Gold Coast's identity crisis as the fact that it is not 'an easily definable place with a singular identity, even though it might appear to lend itself to easy typecasting'. This indicates a need for a study exploring the tension between the marketed or imposed identity of the Gold Coast and the self-identified social, cultural, physical and aesthetic identities assumed by Gold Coast residents. Therefore, this paper explores how the Gold Coast's identity is different to different people and examines the perceptions of visitors and residents based on surveys conducted in April 2011.

Popular media has presented the Gold Coast to viewers as a family-friendly holiday destination, an economically vibrant city, and a hotbed of criminal activities (Stockwell, 2011). In fact in almost all film and television dramas featuring the Gold Coast as a backdrop 'cast the Coast as a scene of the crime in a range from serious felony such as murder and terrorism through to minor misdemeanors such as underage drinking' (Stockwell, 2011, p. 286). In fact, in 2011, following a string of crimes in the city that were widely 
publicised throughout Australia via televised news programmes and current affairs programmes, the ABC described the Gold Coast as the 'Crime Capital' of Australia (Smail, 2011).

The Gold Coast has been popular with domestic and international film and television directors for more than 50 years (O'Regan \& Ward, 2006). Ward and O'Regan (2009, p.222) argue that the city's 'rapid development as one of the premier tourist destinations in Australian tourism is partly attributed to the state government's vigorous promotion of the [film] industry to offset a decline in primary production'. The dichotomy of images of the Gold Coast shown by tourism marketing agencies, and television and film producers emphasises the tension between the numerous competing discourses identified by Griffin (1998).

City identity can be examined from a number of political, economic and cultural perspectives including the way it has been perceived by residents and visitors. While residents derive the city's identity from their experience of it, for visitors various branding schemes used to sell the city have an important role in constructing the identity. Sometimes the images viewed from the inside and the outside do not overlap. Insiders and outsiders may focus on certain aspects and images of a city and not see the complete picture. In places like the Gold Coast this may result in a prejudice against the city and investment and disinvestment decisions may be made based on incomplete or inaccurate information. Thus, we hypothesise that visitor and resident perceptions of the city will be different.

\section{Mirror Mirror on the Wall - City Identity, Image and Branding}

City identity and city image are both constructed ideas that are 'tied to a real or ideal landscape' (Arreola, 1995, p.1). City identity is a social construct created by individuals based on their exposure (through media, word of mouth, pictures, etc.) to and experiences of the city to interpret and make sense of it (ButinaWatson, 2007; Lynch, 1993). However, the perceived image of a city may not accurately reflect its true identity. Rather, the image perceived by individuals is likely to be based on a mélange of experiences, images projected to them through marketing and city branding and history. City identity is a means for cities to differentiate themselves from other destinations. City image builds upon the existing city identity and incorporates the branding of the city to meld the reality of the city with the idealism of marketing professionals, city councils and government bodies (Kavaratzis \& Ashworth, 2005). City image is consequently a marketing construct based on various purposely chosen values, representations, ideas and impressions relevant to a city that are used to 'sell' or portray the city in a certain way to different consumer groups. Although the two concepts build and evolve congruently, there is a risk when introducing falsified (or more usually highly exaggerated) images of a city that 'the identity of a city is not necessarily the same as the image that individuals perceive' (Arreola, 1995, p.1).

Despite the significant number of studies discussing place identity (Butina-Watson \& Bentley, 2007; Twigger-Ross \&. Uzzell, 1996; Valera \& Guardia, 2002), few clearly define the term or explore its importance in planning decisions. Relating the concept of personal identity to a place, Amundsen (2001, p.10-11) suggests that place identity is a contextual social construct which consists of four primary elements:

- 'Spatial qualities that distinguish the place from others (location, infrastructure, communication 
and architecture),

- Characteristics or qualities of inhabitants that distinguish them from inhabitants of other places (values, customs, physical appearance),

- Social conditions and social relations between the inhabitants,

- Culture and/or history, seen as a unifying element that again connects the inhabitants to tradition and ... distinguish them from others'.

The literature currently fails to adequately acknowledge, analyse and discuss the role of branding or marketing of cities in the formation of a city or place image. This paper argues that city identity can be defined through the combination of the four elements identified by Amundsen (2001) and is interpreted by visitors and residents through the lens of city branding to create a uniquely perceived city image.

For the purposes of this research our understanding of identity is drawn from organisational psychology. There is a large body of research in the field of organisational psychology, which relates to organisational identity and identification, and the differences between identity, image and their interaction (Albert et al., 2000). The field of organisational psychology defines identity as that which is central, enduring and distinctive about an organisation's character' (Gioia et al., 2000, p.63). Image as defined by organisational psychology is construed externally to the corporation and reflects the way in which those within the organisation believe outsiders perceive the organisation (Albert et al., 2000). One of the main purposes of city branding is to project the desirable perceived identity of the city to potential visitors to attract them to spend more time in the environs. The defining attributes of identity are those which may be regarded as central, enduring and distinctive about the city. The process of branding and marketing a city attempts to integrate the 'reality' of the city with the medium of idealistic imagery.

A city's identity can be based upon the mixture of advertising representations and narratives of the city shown to its inhabitants and outsiders. Although this claim has a degree of common sense, there is very little discussion of the influence of branding in complex construction of a city identity in the urban or identity literature. Branding is a means of marketing a city by differentiating it from other cities in order to attract visitors and utilises a 'specifically designed place identity and then promotes it to identified markets' (Kavaratzis \& Ashworth 2004, p.506). Cities are increasingly turning to the tool of branding to differentiate themselves. This indicates that branding in fact contributes to the city's perceived identity and consequently the city's image. In arguing the importance of city branding, Dinnie (2003, p.3) asserts that 'the unbranded [city] has a difficult time attracting economic and political attention and that image and reputation are becoming essential parts of [city's] strategic equity'.

Branding draws upon Amundsen's four elements to sell a favourable image of the city to residents and visitors, making it possible to manufacture an image of the city biased towards enticing various age, interest and experience groups (visitor or resident) to 'consume' the city as a product. However, branding and interpretation of cities is not without bias or motivation. Consequently the identity portrayed through marketing schemes to tourists may not be consistent with the identity experienced by the residents of the city and this is what our case study sets out to explore. 


\section{Methods}

Currently, no established method exists to measure city identity or image in a survey instrument. There are however numerous qualitative approaches that rely on subjective or anecdotal methods to measure the blurry interface between self and place-identity (Dukerich et al., 2002). In creating a measure for this paper, inspiration was drawn from organisational psychology because its practice has sought to define both small companies and multi-national corporations. Like cities, large organizations have often ill-defined multiplicities of purposes, interests and means of selling their products which are not always self-evident. Woolworths is an example. Best known for its grocery sales, the company is in fact Australia's largest operator of poker machines (Horin, 2011). Organisational psychology utilises employee questionnaires which focus on the way employees and outsiders view a company by determining the attractiveness of the organisation, attractiveness of the organisation's construed external image (branding, marketing and reputation), and the degree to which employees identify with the company (Dukerich et al., 2002). These factors indicate that organisational psychology methods are highly applicable to understanding the relationship between city identity and city image.

In order to measure the perceptions of Gold Coast residents and visitors, an intercept questionnaire containing questions designed to extrapolate both quantitative and qualitative information from participants was constructed. Whilst this method is limited in relation to the theoretical issues raised by organizational psychology and place-identity, it is used as a diagnostic tool rather than a comprehensive review here. More work is necessary to develop such comprehensive methods. The surveys were administered in two locations: one in high proximity to tourist accommodation, a shopping centre and recreation facilities (Cavill Avenue Mall and Surfers Paradise Foreshore), and the other in an area close to offices, local shopping and local parklands (Southport Broadwater Parklands and the main street in Southport: Scarborough Street) . These locations were chosen to capture mainstream visitors. While surveys conducted in only two locations may bias the results of residents, we expect that the similarity of resident and visitor perceptions will be the highest in these central areas close to visitor attractions. We expect that difference of perceptions is only going to increase between visitors and residents when we go further from these central locations.

429 subjects were intercepted and 203 of them participated in the surveys at the two locations during a peak tourist period (Easter Public Holiday weekend and April school holidays: April 19-30, 2011). The overall response rate was $47 \%$ with residents less likely (45\%) than visitors (51\%) to participate in the survey. The number of respondents was considered sufficient because it was able to demonstrate a statistically significant difference between the two sample groups on several key points with a 1-5\% confidence level. Although a larger sample population may have shown greater discrepancies between resident and visitor perceptions, the high confidence levels indicate that for the purposes of indicating difference this sample size was statistically sufficient (Veal, 2006). Age and gender information of the nonparticipants were recorded to check for participation bias. There was no statistically significant difference between respondents and non-respondents in age or gender. 101 of the respondents were residents and 102 were visitors. Visitor and resident participants were provided with a two page general questionnaire and a single page questionnaire containing more specific questions relevant to their selfidentified visitor/resident status.

Quantitative data were analysed using statistical methods. The analysis of the qualitative responses 
involved utilising a grounded theory approach consisting of a three step coding process: open, axial and selective coding. Open coding disaggregated the data into separate units of measurement or categories (Veal, 2006; Flick, 2006). The list of codes generated by the open coding process was reviewed and similar or related concepts were grouped together (axial coding). This refined list was then selectively coded, which enabled the finalisation and further refining of the codes into core groups of codes (Flick, 2006). These core groups formed the basis of discussion and theory relating to visitor and resident perceptions of of Gold Coast city identity and city image.

\section{Overview of the Respondents}

The residents who responded to the survey were evenly spread regarding their gender (50 females, 51 males) and age, with only the 16-25 age bracket represented by a greater proportion of respondents when compared to other age brackets. Approximately $28 \%$ of residents surveyed have lived on the Gold Coast for more than 21 years, whilst only $9 \%$ of respondents were born in the city. This indicates that $91 \%$ of the residents were not originally from the Gold Coast and $29 \%$ of them came from within South East Queensland (SEQ)(Brisbane, Toowoomba, Logan, etc). The respondents who had moved to the Gold Coast nominated their most common reason for moving to the city as work (34\%) and the city's lifestyle (22\%). Interestingly, $18 \%$ of the Gold Coast residents had moved to the city for the lifestyle in combination with at least one other deciding factor including work, study, retirement, other and health.

Among visitors 48 females and 54 males completed the questionnaire. The age of visitor participants was heavily weighted in the younger age groups with $34 \%$ in the $16-25$ and $27 \%$ in the $26-35$ age bracket. In contrast, the 56-65 age bracket contained only $2.9 \%$ of participants and the $65+$ age bracket was represented by $6.8 \%$ of participants. A large number of visitors earned less than $\$ 25,000$ per annum (39\%), with increasingly smaller groups earning greater amounts. Among residents a similar portion of participants earned less than $\$ 25,000$ per annum (31\%) and the mean annual income was between $\$ 25,001-\$ 50,000$.

The bulk of visitors surveyed were international (43\%) with smaller numbers of interstate (27.5\%), intrastate (6\%) and SEQ visitors (22\%). Just under half of the visitors surveyed first visited the Gold Coast during the 1990 s and 2000s (49\%), and 34\% in the past year. Fewer participants indicated that they had first visited the Gold Coast between the 1950s and 1960s (4\%) and the 1970s and 1980s (11\%). None of the visitors questioned had visited the Gold Coast prior to 1950. Furthermore, many of the visitors surveyed had visited the Gold Coast more than once, with only one quarter nominating this as their first visit. For $29 \%$ of visitors it was their second or third visit, $11 \%$ indicated it was their fourth or fifth visit and $33 \%$ had visited the city more than six times. A great majority of the visitors were staying along the coastline $(70 \%)$ while the rest were distributed evenly in other parts of the city. Unsurprisingly, the most commonly stated purpose for visiting the city was pleasure (66\%) followed by visiting family or friends $(15 \%)$, for business $(2 \%)$, other reasons (2\%), and combinations of these.

\section{Perceptions of City Image}

To compare the perceptions of residents and visitors regarding the image of the Gold Coast, a series of questions on a Likert Scale asked the respondents how strongly they associated a number of attributes such as the beach or multiculturalism with the Gold Coast as a city. The respondents were then asked to use the same scale to indicate how well a further set of statements described the city. Significance testing 
through a two-tailed t-test was carried out to compare the mean association or agreement of the two sample groups. The independent variable was whether the participant was a resident or visitor to the Gold Coast and the dependant variable was the participant's perception of the Gold Coast and its identity as a city.

The results of the study can be summarised into three primary conclusions. Foremost, the results indicate that there are some statistically significant differences in the perception of the Gold Coast city image by visitors and residents. The differences in perception appear in three of Amundsen's four elements of city identity, namely spatial qualities, inhabitant characteristics, social conditions and history or culture. Secondly, the results suggest that visitors and residents do not rely equally on Amundsen's four elements of city identity to form an image of the city. The city's identity may in fact be strongly perceived through one or several of the elements whilst having little to no reliance on other elements and this accounts for the differences between resident and visitor perceptions. Finally, the significant differences observed indicate where current marketing schemes are failing or succeeding. Adjustments may be made if deemed necessary in the future to present a more comprehensive and diverse image of the city.

The data as a whole indicate that there are some statistically significant differences in visitor and resident perceptions of the Gold Coast; where the responses do not differ significantly may be partially explained by the high percentage of residents who migrated from other locations to live in the city. Moreover, this difference supports the inference that, the conflicting images portrayed by the different tourism bodies regarding the city's image have contributed to differing visitor and resident understandings of the Gold Coast. The three primary agencies involved in marketing the city show different elements of the city in their materials. Gold Coast Tourism works collaboratively with Tourism Queensland and is a 'not-for-profit, membership based, destination marketing organisation structured to promote the city as a leisure and business event destination' (Gold Coast Tourism, 2011). The Gold Coast City Council Economic Development Branch, also known as Business GC, exists separately to Gold Coast Tourism and promotes the development of industry within the city (Business GC, 2009). The images used by Gold Coast Tourism and Tourism Queensland are attraction, beach and holiday focused, whilst Business GC tends to use a more diverse range of images focusing on industry and lifestyle.

The data conclusively indicate that the respondents perceived the Gold Coast as unique, with 91\% of residents and $95 \%$ of visitors considering the Gold Coast as distinctly different from other tourist cities. Participant responses also provide valuable insight into the Gold Coast's identity and the way in which visitors and residents gain a sense of place through their experiences of the city's spatial qualities, inhabitants, social conditions and relations and historical and cultural context. We expect sharper differences between resident and visitor perceptions if the resident respondents are born and raised on the Gold Coast. Since most of the respondents were not, they may still be holding an outsider's perspective when it comes to the image of the city.

An examination of the rankings of average Likert scores associated with each attribute of the Gold Coast shows that the primary difference between the visitor and resident attribute rankings and subsequently perception of city image is the level of association of the hinterland with the city (Table 1). Residents identified the Gold Coast hinterland as iconic to a greater degree than did visitors, with an average Likert 
score of 3.77 out of 5 compared to the visitors' average score of 3.07. The higher average resident score supports the hypothesis that residents are more aware of their city's geographic layout, areas of interest and surroundings.

Table 1: Visitor and Resident Ranking of the Gold Coast's Attributes

\begin{tabular}{|l|c|l|c|}
\hline \multicolumn{1}{|c|}{ Visitor Association } & $\begin{array}{c}\text { Average } \\
\text { Likert Score }\end{array}$ & \multicolumn{1}{|c|}{ Resident Association } & $\begin{array}{c}\text { Average } \\
\text { Likert Score }\end{array}$ \\
\hline 1. The beaches and surf & 4.50 & 1. The beaches and surf & 4.62 \\
\hline 2. The tourist strip & 4.31 & 2. The tourist strip & 4.23 \\
\hline $\begin{array}{l}\text { 3. The relaxed/laidback } \\
\text { lifestyle }\end{array}$ & 4.25 & 3. The tourist attractions & 4.17 \\
\hline 4. The tourist attractions & 4.18 & $\begin{array}{l}\text { 4. The relaxed/laidback } \\
\text { lifestyle }\end{array}$ & 4.06 \\
\hline 5. The sub-tropical climate & 3.88 & 5. The sub-tropical climate & 4.01 \\
\hline 6. The architecture & 3.47 & 6. The hinterland & 3.77 \\
\hline 7. The multiculturalism & 3.43 & 7. The architecture & 3.70 \\
\hline $\begin{array}{l}\text { 8. The availability of business } \\
\text { opportunities }\end{array}$ & 3.24 & 8. The multiculturalism & 3.24 \\
\hline \begin{tabular}{l} 
9. The hinterland \\
\hline
\end{tabular} & 3.07 & $\begin{array}{l}\text { 9. The availability of business } \\
\text { opportunities }\end{array}$ & 3.21 \\
\hline
\end{tabular}

The application of a two-tailed t-test indicated a statistically significant difference of perception between the residents and visitors in four attributes: the hinterland $(p<0.01)$, the city's architecture $(p<0.05)$, the relaxed, laidback lifestyle and its multiculturalism (both $p<0.10)$ (Table 2). It is important to note that the two attributes that returned a highly significant $(p<0.05)$ difference in perception were spatial attributes. This leads to the inference that city image and particularly the Gold Coast's city image relies more on a person's spatial awareness, experiences and perceptions of their environs than the other elements of Amundsen's city identity.

Table 2: Two-tailed T-Test of Visitor and Resident Association of Gold Coast Attributes

\begin{tabular}{|c|c|c|c|c|c|c|c|c|c|}
\hline & \multicolumn{5}{|c|}{ Spatial Qualities } & \multirow{2}{*}{ 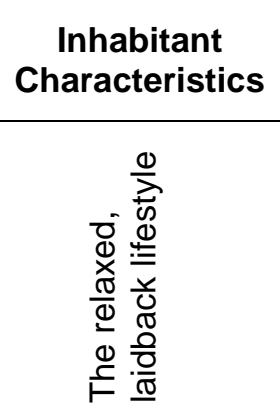 } & \multirow{2}{*}{ 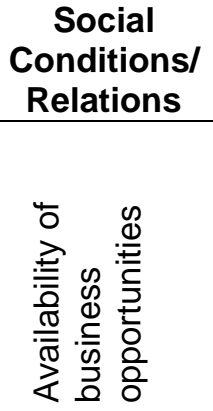 } & \multicolumn{2}{|c|}{$\begin{array}{l}\text { Culturel } \\
\text { History }\end{array}$} \\
\hline & 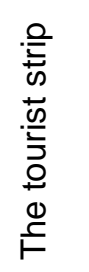 & 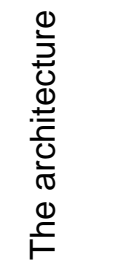 & 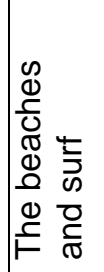 & 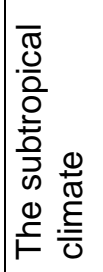 & 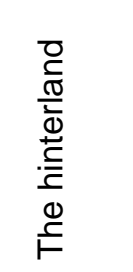 & & & 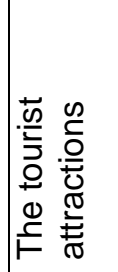 & 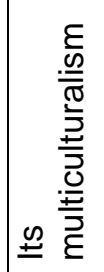 \\
\hline $\begin{array}{r}\text { Visitor Average } \\
\text { Likert Score }\end{array}$ & 4.31 & 3.47 & 4.50 & 3.88 & 3.07 & 4.25 & 3.24 & 4.18 & 3.43 \\
\hline $\begin{array}{r}\text { Resident Average } \\
\text { Likert Score }\end{array}$ & 4.23 & 3.70 & 4.62 & 4.01 & 3.77 & 4.06 & 3.21 & 4.17 & 3.24 \\
\hline $\mathrm{P}(\mathrm{T}<=\mathrm{t})$ two-tail & 0.21 & $0.03^{\star \star}$ & 0.46 & 0.61 & $0.00^{\star \star \star}$ & $0.08^{\star}$ & 0.72 & 0.57 & $0.09^{\star}$ \\
\hline $\begin{array}{l}* \star \text { Significant at } 0.0 \\
\text { * Significant at } 0.0 \\
\text { * Significant at } 0.1\end{array}$ & $\begin{array}{l}\text { level } \\
\text { level } \\
\text { evel }\end{array}$ & & & & & & & & \\
\hline
\end{tabular}


The t-test indicated that residents and visitors had entirely different perceptions of the Gold Coast and its relationship to the hinterland (Table 2). The scores were relatively neutral for visitors (3.07) and more positive leaning for residents (3.77), implying that the hinterland is a stronger element of the residents' perception of the city than the visitors'. The p-value of 0.00 for the hinterland provides certainty that the difference is so significant that sample error could not have caused the variation.

Participants were also asked to indicate on a Likert scale the degree to which they agreed with a series of statements describing the Gold Coast and its residents, the results of which were also subjected to a twotailed t-test. Three of the nine statements returned t-test scores confirming three of the hypotheses: Gold Coasters do not visit Surfers Paradise, the Gold Coast lacks defining architecture and the Gold Coast is more than a tourist location (Table 3). The results for resident and visitor perceptions of architecture are contradictory as shown in Tables 3 and 4 . This might be due to participants misunderstanding the wording of the question or a low awareness of architecture within the city.

The implications of this are that visitors' perceptions of the city may be completely limited to their experience of or exposure to one urban environment such as Surfers Paradise and consequently they may be unaware of the other facilities, attractions and diversity that the Gold Coast offers. The results indicate that residents and visitors perceive the Gold Coast slightly differently at a spatial level regarding urban attributes (specifically architecture) and nature-based attributes (the hinterland), but similarly regarding geospatial attributes.

Table 3: Two-tailed T-Test of Visitor and Resident Levels of Agreement with Descriptions of the Gold Coast

\begin{tabular}{|c|c|c|c|c|c|c|c|c|c|}
\hline & \multicolumn{2}{|c|}{$\begin{array}{c}\text { Spatial } \\
\text { Qualities }\end{array}$} & \multicolumn{3}{|c|}{$\begin{array}{c}\text { Inhabitant } \\
\text { Characteristics }\end{array}$} & \multirow{2}{*}{ 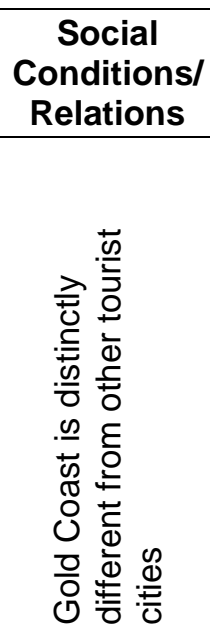 } & \multicolumn{3}{|c|}{ Culture/History } \\
\hline & 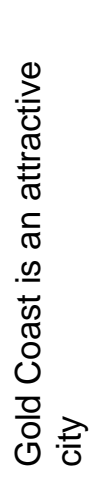 & 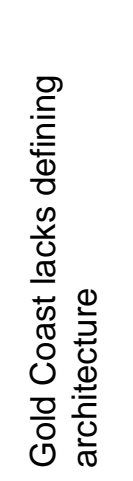 & 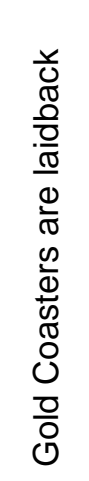 & 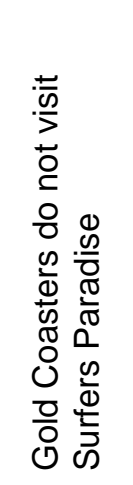 & 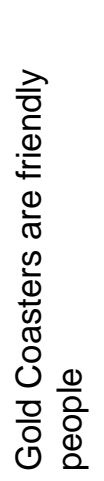 & & 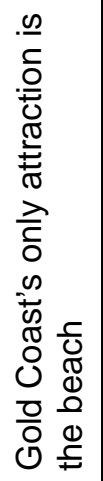 & 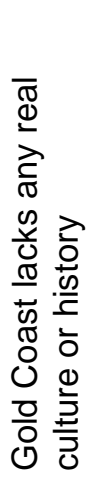 & 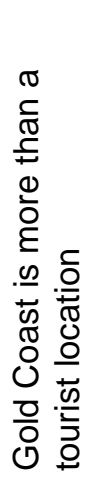 \\
\hline $\begin{array}{r}\text { Visitor Average } \\
\text { Likert Score }\end{array}$ & 3.73 & 2.91 & 3.84 & 2.74 & 3.80 & 3.57 & 2.42 & 3.13 & 3.53 \\
\hline $\begin{array}{r}\text { Resident Average } \\
\text { Likert Score }\end{array}$ & 3.49 & 3.27 & 3.65 & 3.27 & 3.75 & 3.62 & 3.48 & 3.11 & 3.82 \\
\hline $\mathrm{P}(\mathrm{T}<=\mathrm{t})$ two-tail & 0.15 & $0.01^{\star \star \star}$ & 0.20 & $0.00^{\star \star \star}$ & 0.51 & 0.68 & 0.72 & 0.73 & $0.05^{\star \star}$ \\
\hline
\end{tabular}

There is a statistically significant difference in the responses of residents and visitors to the statement 'Gold 
Coasters do not visit Surfers Paradise'. Visitors were inclined to disagree (Average: 2.74) whilst residents tended to agree with the statement (Average: 3.27) (Table 3). The t-test provided a p-value of 0.00 indicating that the difference in perception is statistically significant and not likely to be caused through sample bias or error. This is likely to be due to the amount of time visitors had spent on the Gold Coast, the potentially limited number of residents they had interacted with or observed during their stay and their pre-formed perceptions of the city. The overall lack of responses to the open ended questions relevant to the Gold Coast inhabitants and their characteristics indicate that for residents and visitors, inhabitant characteristics play a minor role in forming an image of the city as a whole.

The following sections discuss the responses to open-ended questions on Amundsen's four elements of city identity: spatial qualities, inhabitant characteristics, social conditions and social relations and culture/history.

The spatial qualities of the Gold Coast were the primary foundation of the image of the city perceived by both residents and visitors. Approximately $42 \%$ of visitor and resident responses mentioned spatial attributes such as the city's geospatial location, natural attributes, and urban attributes as the basis for the Gold Coast being distinctly different to other locations or cities. Responses regarding the city's spatial qualities were broadly grouped into three categories shown in Table 4.

Table 4: Gold Coast's Spatial Qualities According to Its Residents and Visitors

\begin{tabular}{|l|l|c|c|}
\hline $\begin{array}{l}\text { Primary Response } \\
\text { Categories }\end{array}$ & \multicolumn{1}{|c|}{ Example Responses } & \multicolumn{1}{|c|}{$\begin{array}{c}\text { Mentioned in \% of } \\
\text { Responses }\end{array}$} \\
\cline { 2 - 4 } & \multicolumn{1}{|c|}{ Residents } & Visitors \\
\hline Geospatial Location & $\begin{array}{l}\text { Proximity to the beach, hinterland areas, capital cities, } \\
\text { facilities }\end{array}$ & $10 \%$ & $3 \%$ \\
\hline $\begin{array}{l}\text { Nature-based } \\
\text { Attributes }\end{array}$ & $\begin{array}{l}\text { The beach, climate, coastal features, hinterland, the 'green } \\
\text { behind the gold' }\end{array}$ & $9.5 \%$ & $14 \%$ \\
\hline Urban Attributes & $\begin{array}{l}\text { Architecture, city design, city functionality, transport, } \\
\text { infrastructure }\end{array}$ & $23 \%$ & $25 \%$ \\
\hline
\end{tabular}

Urban attributes were the most commonly nominated spatial attribute by residents, followed by the city's nature-based attributes and geospatial attributes. Residents and visitors alike identified urban attributes, particularly the urban form of the city (development along the coastline, suburban sprawl, high rises) as being distinctly unique about the Gold Coast. A plethora of urban attributes were identified to a lesser degree including the city's age, its distinctive lack of a primary central business district, sparsity of population and cleanliness. The Gold Coast's architecture, entertainment precincts, lack of infrastructure, fast paced growth, and low congestion were associated with the city by fewer than two residents for each attribute. Visitors also identified the city's geospatial relationship with the coastline and beaches as a distinguishing feature of the city. As the surveys were undertaken along the coastline, this was not a surprising response and is likely to be due to respondents contemporaneously observing the surrounds in which they completed the survey instrument and the purpose for which they came to the survey location (i.e. to visit the beach). The primary geospatial attribute identified by residents as unique about the city was its proximity to the nearby capital city of Brisbane, other cities (via domestic and international airports within 
or near the city), facilities and nature (predominantly the beach).

The characteristics of the Gold Coast's inhabitants were the least identified elements by both residents and visitors as defining or distinctive about the city when compared with Amundsen's other elements of city identity. However, residents mentioned inhabitant characteristics as unique to the city twice as frequently as visitors with $8.8 \%$ of referring to them as opposed to only $4.3 \%$ of the visitors. The responses encompass four general categories outlined in Table 5.

Table 5: Gold Coast's Inhabitant Characteristics According to Its Residents and Visitors

\begin{tabular}{|l|l|c|c|}
\hline \multirow{2}{*}{$\begin{array}{c}\text { Primary Response } \\
\text { Categories }\end{array}$} & \multicolumn{1}{c|}{ Example Responses } & \multicolumn{2}{c|}{$\begin{array}{c}\text { Mentioned in \% of } \\
\text { Responses }\end{array}$} \\
\cline { 2 - 4 } & \multicolumn{1}{c|}{\begin{tabular}{c}
\multicolumn{1}{c|}{ Residents } \\
Visitors
\end{tabular}} \\
\hline Attitude & Materialistic, happy, friendly, 'zen' locals & $3.7 \%$ & $3.6 \%$ \\
\hline Demographic & $\begin{array}{l}\text { Large numbers of residents were not born on Gold } \\
\text { Coast, more tourists than residents, greater diversity } \\
\text { in residents }\end{array}$ & $3.0 \%$ & $0.1 \%$ \\
\hline Dress & Casual dress code, brighter clothing & $1.6 \%$ & $0.0 \%$ \\
\hline Physical Characteristics & Beautiful people & $0.5 \%$ & $0.0 \%$ \\
\hline
\end{tabular}

Visitors identified the Gold Coast resident attitude as the only inhabitant characteristic contributing to the city's distinctness. Residents also placed the greatest emphasis on inhabitant attitudes, with individuals identifying residents' positive outlook on life, good values, and materialistic, friendly and hospitable residents (Table 5) but also mentioned demographic characteristics of Gold Coasters as distinctive as well. Although there were limited responses by visitors relating to inhabitant characteristics, the primary characteristic they identified was the friendly attitude of residents they had interacted with. Residents' physical attributes and sense of dress were not mentioned in visitor responses and were infrequently referred to in resident responses. It is interesting to note that while respondents identified attitude as a distinctive feature of the Gold Coast residents some of the attitudes they refer to are at polar opposites (materialistic vs. 'zen' locals).

In addition to the results above, responding to the question 'Are Gold Coasters unique in their culture? How/How not?', nearly all the respondents described inhabitant characteristics, particularly attitude (Figure 1). Approximately $45 \%$ of residents and $25 \%$ of visitors described attitude traits, specifically the laidback attitude and lifestyle of residents as the most unique element of resident culture. These responses represent the interaction and interreliance of Amundsen's elements in forming an image of a city. Theoretically each element can be discussed separately, but practically there is a degree of crossover and interaction. 


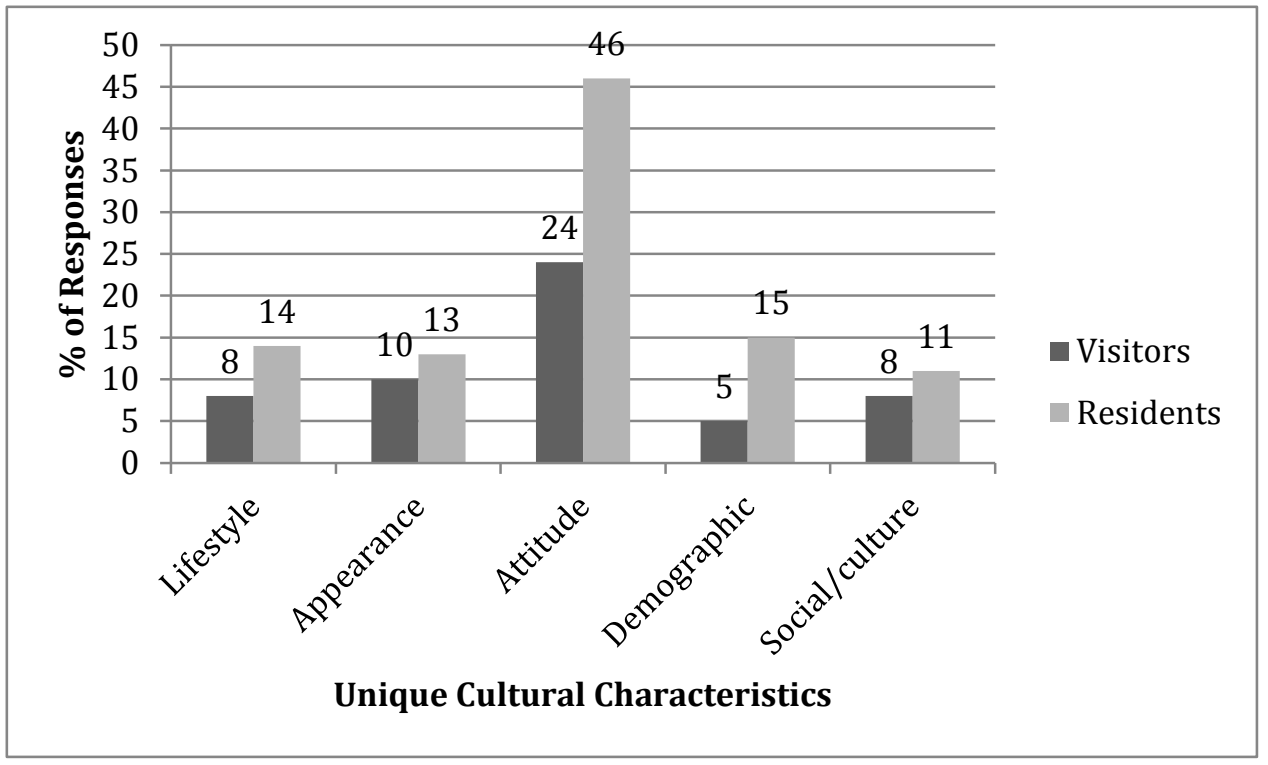

Figure 1: Unique Characteristics of the Gold Coast Culture Identified by Residents and Visitors

The social conditions and social relations of the Gold Coast and its residents were the second most distinctive city identity element of the Gold Coast after spatial qualities for both residents and visitors. Visitors had a slightly stronger association with the social conditions and relations with $39.1 \%$ related responses compared to $31 \%$ resident responses. The responses were grouped under four encompassing categories described in Table 6.

Table 6: Gold Coast's Social Conditions and Social Relations According to Its Residents and Visitors

\begin{tabular}{|l|l|c|c|}
\hline \multicolumn{1}{|c|}{$\begin{array}{c}\text { Primary } \\
\text { Response } \\
\text { Categories }\end{array}$} & \multicolumn{1}{|c|}{ Example Responses } & \multicolumn{2}{c|}{$\begin{array}{c}\text { Mentioned in \% of } \\
\text { Responses }\end{array}$} \\
\cline { 3 - 4 } & \multicolumn{1}{|c|}{ Residents } & Visitors \\
\hline Lifestyle & $\begin{array}{l}\text { Laidback, beach lifestyle, variety of social groups, outdoor } \\
\text { lifestyle, safety, affordability, relaxed, family oriented }\end{array}$ & $17 \%$ & $26 \%$ \\
\hline $\begin{array}{l}\text { Employment/Ind } \\
\text { ustry }\end{array}$ & $\begin{array}{l}\text { Development and service industries the primary } \\
\text { employers, unemployment, tourism main source of city } \\
\text { income }\end{array}$ & $4.7 \%$ & $1.4 \%$ \\
\hline Population & Highly transient, busy, tourist focused city attitude & $8.9 \%$ & $10 \%$ \\
\hline Other & $\begin{array}{l}\text { High crime rate, high rises primarily for visitors rather than } \\
\text { residents }\end{array}$ & $1 \%$ & $1.4 \%$ \\
\hline
\end{tabular}

Lifestyle was the most strongly associated component of social conditions and social relations by both residents and visitors (Table 6). Lifestyle factors that were identified as distinctive about the Gold Coast included its beach-focused lifestyle, laidback lifestyle, variety of activities, family oriented nature, its high cost of living and being a nice place to live. In this way the image and the identity appear to be aligned with each other as demonstrated by the congruency of the visitor and resident perspectives. Interestingly, visitors tended to disagree slightly more than residents that the city's only attraction is the beach however the difference is not statistically significant. The high exposure of visitors to brochures and advertising regarding the tourist attractions and other attractions available on the Gold Coast may help to explain this 
trend. Social conditions and relations evidently play a role in forming a perception or image of a city, however they are less influential when compared to the spatial attributes and more influential than the characteristics of a city's inhabitants.

The Gold Coast's culture was the second least distinctive element of the city's identity for visitors and residents. Visitors were fractionally more likely than residents to identify culture as a defining characteristic of the city, with $19.5 \%$ of residents and $16 \%$ of visitors mentioning it in their responses (Table 7 ). Responses were limited to three broad categories.

Table 7: Gold Coast's Culture According to Its Residents and Visitors

\begin{tabular}{|l|l|c|c|}
\hline \multirow{2}{*}{$\begin{array}{c}\text { Primary Response } \\
\text { Categories }\end{array}$} & \multicolumn{1}{|c|}{ Example Responses } & \multicolumn{2}{c|}{$\begin{array}{c}\text { Mentioned in \% of } \\
\text { Responses }\end{array}$} \\
\cline { 2 - 4 } & \multicolumn{1}{|c|}{ Residents } & Visitors \\
\hline Tourism & Tourist-oriented city & $13 \%$ & $12 \%$ \\
\hline Culture & $\begin{array}{l}\text { Multiculturalism, no culture/history, similar culture to Miami, } \\
\text { Florida }\end{array}$ & $5 \%$ & $3.6 \%$ \\
\hline Other & Meter Maids, city of opportunities, not a real city & $1.5 \%$ & $0.07 \%$ \\
\hline
\end{tabular}

Tourism (and the tourist-oriented nature of the city) was the most commonly associated element of the Gold Coast's culture by both residents and visitors, consisting of approximately $70 \%$ of each sample group's responses. This is not surprising considering $25 \%$ of residents are employed in service or tourism related industries and tourism is a primary driver of the Gold Coast's economy (Gold Coast Tourism, 2010).

Visitors and residents were comparable in their perception of the city's culture, ranking multiculturalism as the $7^{\text {th }}$ (visitors) and $8^{\text {th }}$ (residents) strongest associated element of the Gold Coast identity out of a possible nine attributes (Table 1). The t-test revealed a 91\% confidence level, which represents a statistically significant difference in opinion at a $p<0.10$ level (Table 2), allowing the inference that residents and visitors differ in their perception of the city's culture.

\section{Views on City Branding}

Residents and visitors were at a relative consensus on the accuracy of advertising campaigns regarding the Gold Coast and its attractions (Figure 2). Visitors were more inclined to believe that the advertising campaigns were accurate (71\%) when compared to residents (57\%) (Figure 2) whereas a greater percentage of residents (28\%) found the advertising to be inaccurate compared to only $12 \%$ of visitors. This difference indicates that residents are unsurprisingly more aware of the realities of the city and its dayto-day life, whilst visitors are more likely to see a small slice of the city and what life is like within it because of the relatively short time they stay, the limited locations they briefly inhabit and the original purpose and focus of their visit to the Gold Coast. 


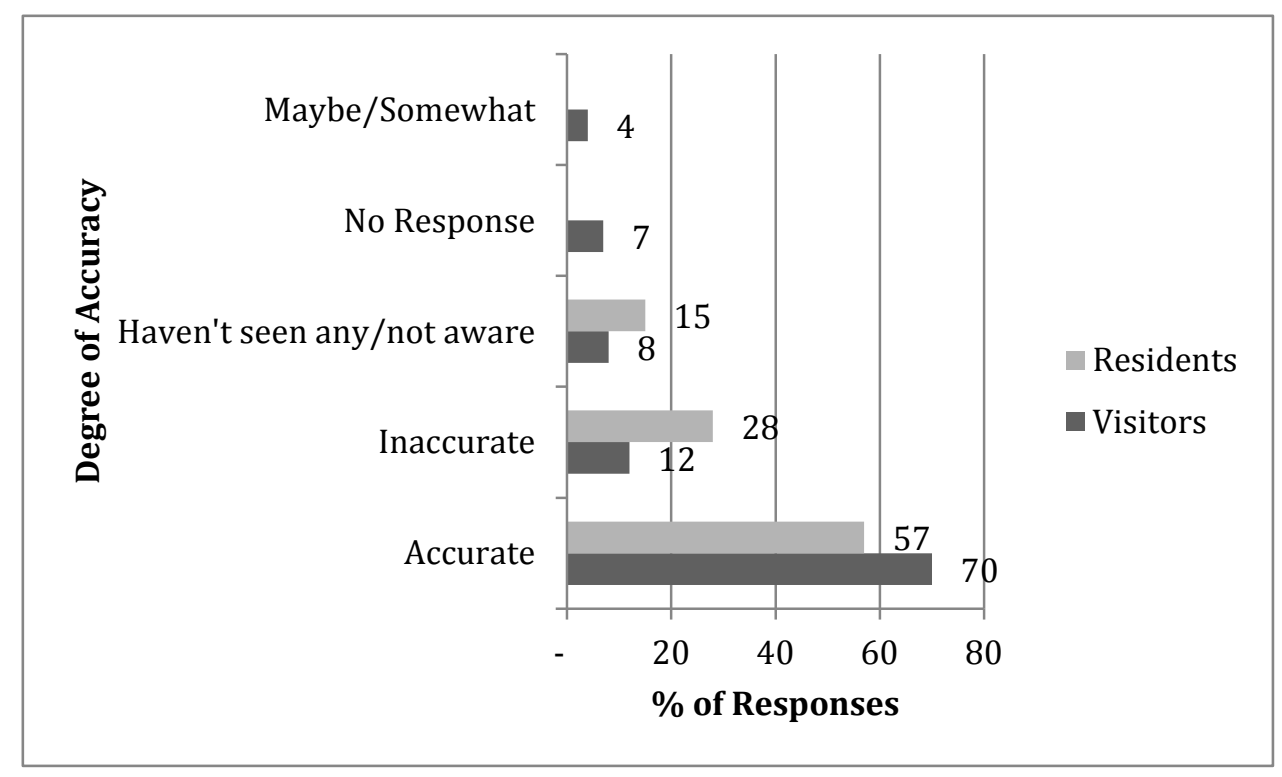

Figure 2: Resident and Visitor Assessment of the Accuracy of Advertising about the Gold Coast

Interestingly, residents were twice as likely (15\%) as visitors (8\%) to be unaware of any advertising for the city (Figure 2). This is likely the result of tourism organisations' focus on international, interstate and interregional tourist markets rather than on residents within the city they are promoting.

Obviously, the advertising is not the sole basis for visitor expectations of the city and other factors such as word of mouth, mass and social media and past experiences may also shape expectations. However, a comparison of visitor expectations of the city and whether those expectations were met provides an insight as to whether advertising is accurately portraying the Gold Coast. Approximately $68 \%$ of visitor' expectations were met with a further $21 \%$ having their expectations exceeded by their experiences of the city. This supports the inference that the advertising of the Gold Coast to potential (and actual) visitors is a relatively accurate depiction of the city, its attractions and experiences that visitors can expect to have whilst staying there.

The minority of visitors (7\%) whose experiences differed from their expectations identified weather as the primary reason for this. The surveys were undertaken after a period of relatively high rainfall in the Gold Coast and thus it is not surprising that visitors identified this as different from their expectations of the city which is advertised to be a sunny location.

Residents were asked to identify the advantages and disadvantages of living on the Gold Coast which, when compared to visitor expectations, provides a comparison of the image and identity of the city as a whole. This comparison of the selective codes support the results provided by the t-test regarding the strength of each of Amundsen's elements in forming the Gold Coast's identity. Spatial attributes were again the most commonly identified attribute by visitors and residents. Visitors focused on urban and naturebased attributes in their expectations, listing the beach and good weather as their greatest expectations with other attributes such as high rises, the city being busy and centred around the beach area also appearing in their responses. Residents also prioritized the beach and good weather as the primary advantages of living in the Gold Coast. Moderate numbers of residents also mentioned the city's high accessibility and proximity to other locations as a significant advantage of the Gold Coast. 
Social conditions and relations, specifically the relaxed and laidback lifestyle, were the second most commonly identified advantage by residents, further reiterating the results of the t-test (Tables $2 \& 3$ ). This differed from visitors who did not particularly focus on the Gold Coast's social conditions or relations in their expectation descriptions. Alternatively, inhabitant characteristics were not considered important to residents in describing the advantages of the Gold Coast, whilst visitors had a moderate focus on them in their responses. Visitors were expecting friendly, laidback and classy residents, surfers and attractive women on the Gold Coast. Fewer residents identified many of the same inhabitant characteristics in their responses. Culture and history were of a similar level of importance to both samples and were identified by a minority of participants as a feature of their expectations or experiences of the city

These results indicate that existing and past advertising campaigns promoting the Gold Coast have been relatively accurate in portraying the city to outsiders. This is supported by the high level of agreement of visitor expectations and resident identified advantages of living on the Gold Coast. However, while the residents found the advertising to be accurate, they did not find it complete. In response to the question 'should advertising of the Gold Coast be improved?' residents stated that the overall emphasis on tourism and the view of the city as a tourist town with images of car races (such as Indy or the GC600), Surfers Paradise and its nightlife and theme parks should be reduced. Residents suggested that there needs to be a greater focus on the unique characteristics of the Gold Coast lifestyle, diversity of attractions (particularly non-beach attractions), the local arts scene and family-friendly activities.

\section{Conclusions}

Inevitably there is a blurring between the nature of identity as a construct of experience and branding as a social construct of a city's image. The crossovers and interplay between image and identity are complex. It is trite to say that each city has one clear identity or experience, as much depends on the social circumstances and history of the people being asked to delineate their experience of the city. Image, which seeks to clarify and perhaps even purify external identity through the process of branding, must of its nature produce one experience. A series of words and pictures, which seek to promote feelings of wellbeing, warmth and attractiveness, must of themselves be simple enough to be readily taken up by the target audience.

While the competing discourses Griffin (1998) notes of the Gold Coast may qualify the contradictions in the city's identity, they also seek to define it. Because of its rich history of growth, change, multiculturalism, gold lame bikinis and development, the Gold Coast's identity is perhaps that, a city with multiple, competing and at times contradicting identities. From these competing identities emerges 'a strong sense of space and place', emphasizing the importance of branding activities in the foundation of a city identity (Griffin, 1998, p.287; Holden, 2011; 2012). The problem is, usually the goal of the agencies that engage in branding is not equally diverse. Agencies trying to sell the Gold Coast as a tourism product have no interest in showing the city in its entirety or correcting the misconceptions. On the contrary, they do not shy away from reaffirming commonly held beliefs. Their economic power enables them to dominate the battle of brands as the results of this study indicate. The primary disparities between resident and visitor perceptions in this study demonstrate the influence of beach focused branding campaigns. Visitors did not relate the hinterland area as being an important part of the Gold Coast, whilst residents ranked it as the sixth most 
iconic attribute of the city. This demonstrates that unfortunately, what works to attract tourists might not work for attracting investment or prospective residents. Further research, particularly on the effects of branding schemes in outsiders' perceptions of the Gold Coast, would be useful to better understand the processes forming the image of the city for outsiders.

\section{References}

Albert, S., Ashforth, B., \& Dutton, J. (2000). Organizational Identity and Identification: Charting New Waters and Building New Bridges. Management Review, 25 (1), 13-17.

Amundsen, H. T. (2001). Articulations of Identity: A Methodological Essay and a Report on Askim and Tidaholm. Østfold, Noord, XXI.

Arreola, D. (1995). Urban Ethnic Landscape Identity. The Geographical Review, 85, 518-534.

Australian Bureau of Statistics (2012). National Regional Profile: Gold Coast Local Government Area Retrieved 23/8/12, from

http://www.censusdata.abs.gov.au/census_services/getproduct/census/2011/quickstat/LGA33430? opendocument\&navpos $=220$

Bradley, N. (2007). Marketing Research: Tools and Techniques. New York: Oxford University Press.

Business GC (2009). Economic Development Strategy 2020. Gold Coast: Gold Coast City Council.

Burton, P. (2009). Growing Pains: Adolescent Urbanism on the Gold Coast. Gold Coast, Urban Research Program.

Butina-Watson, G., \& Bentley, I. (2007). Identity by Design. Oxford: Elsevier.

Dinnie, I. K. (2003). Place Branding: Overview of an Emerging Literature. Tokyo, Temple University Japan.

Dukerich, J., Golden, B., \& Shortell, S. (2002). Beauty is in the Eye of the Beholder: The Impact of Organisational Identification, Identity and Image on the Cooperative Behaviours of Physicians. Administrative Science Quarterly, 47 (1), 507-533.

Edwards, D., T. Grffin, T., \& Hayllar, B (2007). Development of an Australian Urban Tourism Research Agenda. Brisbane, Sustainable Tourism CRC.

Flick, U. (2006). An Introduction to Qualitative Research (Third ed.). London: Sage Publications.

Friedman, J. (1992). The Past in the Future: History and the Politics of Identity. American Anthropologist, 94 (4), 837-859.

Gioia, D., Schultz, M., \& Corley, K. (2000). Organizational Identity, Image and Adaptive Instability. Academy of Management Review, 25 (1), 63-81.

Gold Coast Tourism (2010). "Very Gold Coast, Very GC." Retrieved 12/7/2010, from http://www.verygoldcoast.com.aul

Gold Coast Tourism (2011). "Gold Coast: Famous for Fun." Retrieved 19/1/2011, from http://www.visitgoldcoast.com/

Griffin, G. (1998). The Good, The Bad, The Peculiar: Cultures and Policies of Urban Planning and Development on the Gold Coast. Urban Policy and Research, 16 (4), 285-292.

Holden, G. (2011) 'Sense of Place and Urbanity: Challenges and Interventions at the Gold Coast', Proceedings from the 4th Making the Cities Liveable Conference Noosa (Queensland), 27-29 July.

Holden, G. (2012) 'Authentic Experience and Minor Place-Making', Proceedings from the Designing Places: International Urban Design Conference, University of Nottingham, 02-03 April

Horin, A. (2011). Nanny's Wisdom has Paid off Before, The Sydney Morning Herald, 29 October, p. 18. 
Jones, M. (1986). Sunny Place for Shady People: The Real Gold Coast Story. Sydney: Allen \& Unwin. Kavaratzis, M., \& Ashworth, G. J. (2005). City Branding: An Effective Assertion of Identity or a Transitory Marketing Trick? Tijdschrift voor Economische en Sociale Geografie, 96 (5), 506-514.

Lynch, K. (1993). The Image of the City. Massachusetts: The MIT Press.

McRobbie, A. (1991). Gold Coast Heritage: A Multicultural Triumph. Surfers Paradise: Pan News Pty. Ltd. O'Regan, T., \& Ward, S. (2006). Experimenting with the Local and the Transnational: Television Drama Production on the Gold Coast. Continuum: Journal of Media and Cultural Studies. 20(1), 17-31

Plumwood, V. (1993). Feminism ad the Mastery of Nature. London: Routledge.

Proshansky, H., Fabian, A., \& Kaminoff, R. (1983). Place-Identity: Physical World Socialization of the Self. Journal of Environmental Psychology 3 (1), 57-83.

Smail, S. (2011). 'Gold Coast "Crime Capital of Australia" say police', ABC Radio, http://www.abc.net.au/am/content/2011/s3274207.html

Stockwell, S. (2011). Crime capital of Australia: The Gold Coast on Screen. Studies in Australasian Cinema, 5(3), 281-292

Twigger-Ross, C., \& Uzzell, D. (1996). Place and Identity Processes. Journal of Environmental Psychology, 16, 205-220.

Valera, S., \& Guardia, J. (2002). Urban Social Identity and Sustainability: Barcelona's Olympic Village. Environment and Behaviour, 34 (1), 54-66.

Veal, A. J. (2006). Research Methods for Leisure and Tourism (Third ed.). Sydney: Prentice Hall: Financial Times.

Ward, S., \& O'Regan, T. (2009). The Film Producer as the Long-stay Business Tourist from a Gold Coast Perspective. Tourism Geographies: An International Journal of Tourism Space, Place and Environment. 11(2), 214-232 